\title{
A Comparative, Cross-National Analysis of Partner-Killing by Women in Cohabiting and Marital Relationships in Australia and the United States
}

\author{
Jenny Mouzos*1 and Todd K. Shackelford ${ }^{2}$ \\ ${ }^{1}$ Australian Institute of Criminology, Canberra, ACT, Australia \\ ${ }^{2}$ Florida Atlantic University, Davie, Florida
}

\begin{abstract}
Using a national-level United States database, T. K. Shackelford [Partner-killing by women in cohabiting relationships and marital relationships. Homicide Studies 5: 253-266, 2001] calculated rates of partner-killing by women by relationship type (cohabiting or marital), by partner ages, and by the age difference between partners. Men in cohabiting relationships were 10 times more likely to be killed by their partners than were married men. Within marriages, the risk of being killed by a partner decreased with a man's age. Within cohabiting relationships, in contrast, middle-aged men were at greatest risk of being killed by their partners. The risk that a man will be killed by his partner generally increased with greater age difference between partners. We sought to replicate the findings of Shackelford [2001] using national-level data held as part of the National Homicide Monitoring Program (NHMP) at the Australian Institute of Criminology in Australia. The NHMP holds data on over 3,500 homicides that occurred in Australia between 1989 and 2000. Despite the higher rate of partner-killing in the United States, and despite other cultural differences between the two countries (for example, the prominent gun culture in the United States), we replicated the key patterns with the Australian data. Aggr. Behav. 30:206-216, 2004. (C) 2004 Wiley-Liss, Inc.
\end{abstract}

: : : : : : : : : : : : : : : : : : : : : : : : : :

Keywords: intimate partner homicide; cohabitation; marriage; Australia; United States

Much research has examined homicide in intimate relationships [Browne, 1997; Browne and Williams, 1993; Carcach and James, 1998; Cardarelli, 1997; Daly and Wilson, 1988; Ewing, 1997; Mouzos, 1999, 2001a; Shackelford et al., 2000]. Although the findings of this research can be used to guide efforts to prevent intimate partner homicide, further research is required to identify key predictor variables, such as marital status and age, that increase the risk of intimate partner homicide. A number of researchers have investigated the relationship of marital status to intimate partner homicide. Some argue that, for men, marriage is a form of

*Correspondence to Jenny Mouzos, National Homicide/Firearms/Deaths in Custody Monitoring Programs, Australian Institute of Criminology, GPO Box 2944, Canberra ACT 2601, Australia.

E-mail: Jenny.Mouzos@aic.gov.au; or Todd K. Shackelford, Florida Atlantic University, Department of Psychology, 2912 College Avenue, Davie, Florida 33314. E-mail: tshackel@fau.edu

Received 17 May 2002; amended version accepted 29 January 2003

Published online in Wiley Interscience (www.interscience.wiley.com). DOI: 10.1002/ab.20018 
social control that keeps them from engaging in risky behavior that attends homicide victimization, such as frequenting bars, heavy drinking, and fighting [Breault and Kposowa, 1997]. On the other hand, it has been found that, for women, marriage attends a greater homicide risk than non-marriage [Gartner and McCarthy, 1991; Mouzos, 1999, 2001a, 2001b, 2002].

Recent research has identified differences in the risk of homicide victimization based on the type of intimate relationship between two people who reside together. This research addresses differences in risk for persons in cohabiting relationships versus marital relationships. Following Shackelford [2001], we use the term "cohabiting relationship" because it is the least restrictive label that encapsulates the various terms used to describe two persons involved intimately and who reside together, but are not legally married. Men and women in cohabiting relationships are at a much greater risk for being killed by their partners than are married men and women [Daly and Wilson, 1988; Shackelford, 2001; Wilson et al., 1993; Wilson et al., 1995]. Most of this research has been conducted either in Canada or the United States, and on women as victims, and not as offenders. This raises two issues. The first issue refers to the generalizability of the findings to other countries, such as Australia. The second issue concerns the paucity of research on women as offenders, especially in Australia. Previous research finds that, firstly, men in cohabiting relationships, when compared to men in marital relationships, incur higher rates of homicide victimization by a female partner, and that, secondly, there are age differences associated with the risk incurred. Using national-level Canadian homicide data, Wilson et al. [1993] report that men in cohabiting relationships are about 15 times more likely to be killed by their female partners than are married men. Further research by Wilson and Daly [1994; and see Daly and Wilson, 1988] finds that, within marital relationships, men in their teens and early 20 s are at greatest risk of being killed by a partner. Within cohabiting relationships, in contrast, middle-aged men, in their 40s and 50s, are at greatest risk of being killed by a partner. Finally, Daly and Wilson [1988] report that, in both marital relationships and cohabiting relationships, the age difference between the man and the woman predicts a man's risk of being killed by a partner. Men in both types of relationships are at greater risk of being killed when partnered to women who are either much older or much younger than they are.

Following the work of Wilson et al. [1993, 1995] and Daly and Wilson [1988], Shackelford [2001] set forth to replicate the Canadian findings using national-level United States homicide data. Shackelford [2001] replicated many of the key findings reported in the Canadian studies, further corroborating the finding that men in cohabiting relationships compared to men in marital relationships incur an elevated risk of intimate partner homicide.

Apart from the research in Canada and the United States, no other research has examined the differences in risk of partner killing by women by type of relationship. Being able to identify risks associated with type of relationship and age can help to pinpoint the characteristics of persons most at risk of homicide victimization and offending. This is especially pertinent when examining female perpetrated homicide, as a large percentage of females who kill will kill an intimate partner [see, e.g., Daly and Wilson, 1988]. Unfortunately, there also has been a lack of comparative research in this area.

Comparative research as a whole has been fruitful, with hundreds of comparative studies conducted so far, but few in the area of homicide and specifically intimate partner homicide [see Shackelford, 2001]. Many of these studies are intra-United States comparisons, not comparisons across cultures or nations. The potential value of comparative studies lies in the possibility of identifying both common and unique features of crime, especially lethal 
violence in different countries. Comparative studies also are of great value to public policy because they can provide a novel perspective on a country's crime problem (rates, patterns and so forth) and the ways in which similar problems are experienced and dealt with in other countries.

Given the availability of national-level homicide data and population estimates for both Australia and the United States, we sought to replicate using an Australian database the risk patterns identified by Shackelford [2001] for partner-killing by women in cohabiting and marital relationships in the United States. The rationale for exploring differences in partnerkilling by women in the United States and Australia stems from the need to determine whether the patterns of partner-killing by women observed in the United States also occur in other countries, such as Australia. The identification of common patterns could allow for the extrapolation of prevention policies between like countries. Similarly, age was considered an important variable for calculating relative risk of partner-killing by women by type of relationship given that the risk of homicide victimization varies significantly with both the age of the victim and the age of the offender [see, for example, Mouzos, 2001; Wolfgang, 1958]. Identifying which age group of cohabiting males and married males are at a heightened risk of being killed by their partner also may assist in understanding the reasons behind the elevated risks. Irrespective of relationship type, are the risk patterns similar to those found in homicide victimization overall?

The current study also is important because the replication of findings using Australian data would increase the robustness of the findings from previous research that has examined the risk of partner-killing by women as a function of type of relationship. This is especially important given some of the differences in homicide between the United States and Australia. During 2000, the United States homicide rate of 5.5 per 100,000 persons was almost 3.5 times the rate for Australia [rate of 1.8; Federal Bureau of Investigation, Uniform Crime Reports, 2001, and Mouzos, 2002, respectively]. About 22\% of homicides in Australia are committed with a firearm [Mouzos, 2002], compared to $66 \%$ in the United States [Federal Bureau of Investigation, Uniform Crime Reports, 2001]. As a final example of differences in homicide patterns between the two countries, a greater proportion of homicides occur between intimate partners in Australia [22\%, Mouzos, 2002] when compared to the United States [10\%, Federal Bureau of Investigation, Uniform Crime Reports, 2001].

Despite higher rates of homicide in the United States, the United States and Australia are quite similar in other respects. The general patterns of homicide victimization and offending are similar between the two countries; most homicides occur between persons who know one another, usually a friend or acquaintance, in a residential premise and during the late or early hours of the morning. In both countries, most homicides occur between persons who are not in paid employment at the time of the incident. Males overwhelmingly outnumber females as both victims and offenders in both the United States and Australia [data for United States from Federal Bureau of Investigation, Uniform Crime Reports, 2001; data from Australia from Mouzos, 2002].

Furthermore, the current study adds to the limited existing research on women as homicide offenders, by providing further insight into this under-researched area through the identification of predictor variables such as relationship type. To date, there have been few studies on women who kill in Australia [Lansdowne and Bacon, 1982; Lawrence, 1985; Polk, 1993, 1994; Wallace, 1986; Kirkwood, unpublished dissertation data], and none have examined intimate partner homicide risk for men in cohabiting relationships versus marital relationships. 


\section{METHOD}

\section{National Homicide Data}

Australia. The national-level data for homicide in Australia is derived from the National Homicide Monitoring Program (NHMP) held at the Australian Institute of Criminology (AIC). The NHMP collects details on all homicides that come to the attention of police across Australia's eight states and territories. The NHMP database analyzed for the present project includes all homicides (victims and offenders) for the fiscal years 1989/1990 to 1999/ 2000, providing information on 3,723 homicide victims and 3,783 homicide offenders. Each homicide record includes information about the circumstances of the incident, victim and offender demographics, and the victim-offender relationship. Homicide rates were calculated for both married men and cohabiting men according to population estimates provided by the Australian Bureau of Statistics (ABS), Family Characteristics Survey, 1997 [unpublished data].

United States. Data for the United States were derived from the published findings of Shackelford [2001]. Shackelford [2001] used the Federal Bureau of Investigation's Supplementary Homicide Reports (SHRs) for the years 1976 to 1994 [Fox, 1996], which provided information on 429,729 homicides. SHRs include incident-level data on every reported homicide, including the relationship of the victim to the offender and the ages of the victim and offender. Shackelford [2001] calculated homicide rates for married men and for cohabiting men according to population estimates provided by the United States Census Bureau. For married men, rates were calculated using weighted averages of the 1980 and 1990 census data; for cohabiting men, rates were calculated using weighted averages of the 1980 and 1990 Current Population Survey for unmarried co-resident couples.

\section{Calculation of Homicide Rates}

In this section, we provide examples of how we calculated homicide rates. To calculate the rate per million married couples per annum for a male aged less than 25 years who was killed by a woman aged less than 25 years, we first calculated how many married men aged less than 25 were killed by a woman aged less than 25 years per annum (the numerator). This figure was then divided by the number of couples in the general population (population estimates) who were both aged less than 25 years (the denominator). The resulting figure was then multiplied by one million to obtain the rate.

A similar method was used to calculate homicides rates for cohabiting men, with population estimates for cohabiting couples used instead. Where rates are presented as a function of the man's age or the woman's age (Figures 1 and 2), the population estimates have been halved to represent single members of couples. For example, to calculate the per annum rate of partner killings by women per million married men aged less than 25 years, we first calculated how many married men aged less than 25 years were killed per annum (the numerator). This figure was then divided by the number of married men less than 25 years in the population (the denominator). The resulting figure was then multiplied by one million to obtain the rate.

\section{Procedures}

Statistics for the United States [based on Shackelford, 2001] are presented in this section in parentheses following figures for Australia. Of the over 3,700 homicides included in the 
Table I. Descriptive Statistics of Study Populations

\begin{tabular}{lccccccc}
\hline & \multicolumn{3}{c}{ Australia } & & \multicolumn{3}{c}{ United States } \\
\cline { 2 - 3 } \cline { 6 - 7 } $\begin{array}{l}\text { Descriptive } \\
\text { Statistics }\end{array}$ & Mean Age & $\begin{array}{c}\text { Standard } \\
\text { Deviation }\end{array}$ & Age Range & & Mean Age & $\begin{array}{c}\text { Standard } \\
\text { Deviation }\end{array}$ & Age Range \\
\hline Married victims & 47.0 & 17.1 & $25-88$ & & 41.4 & 12.8 & $17-98$ \\
Married Perpetrators & 42.3 & 12.1 & $25-88$ & & 37.5 & 12.0 & $12-98$ \\
Cohabiting Victims & 36.2 & 11.9 & $18-55$ & & 38.5 & 12.0 & $14-89$ \\
Cohabiting Perpetratprs & 34.0 & 11.8 & $18-55$ & & 34.5 & 11.3 & $15-86$ \\
\hline
\end{tabular}

NHMP database (over 400,000 cases in the United States), there were 52 homicides $(8,077$ in the United States) in which a woman killed the man to whom she was legally married, and 88 homicides (2,054 in the United States) in which a woman killed the man with whom she was cohabiting but to whom she was not married. Homicides involving ex-spouses were excluded from both the Australian and United States data.

Table I presents descriptive statistics for the ages of married and cohabiting victims and perpetrators in Australia and the United States. Victims and perpetrators who were married tended to be older than their cohabiting counterparts. Irrespective of relationship type, the perpetrators tended to be younger than their victims.

\section{RESULTS}

We present results for analyses of Australian data first, followed by the parallel results for the United States data. This presentation strategy allows for a straightforward cross-national comparison of results, including the identification of similarities and differences. The examination of differential risk patterns for married and cohabiting men is divided into three sections. The first section examines the risk of being killed by a partner for married men and for cohabiting men in Australia and in the United States. The second section examines the risk of being killed by a partner for married men and for cohabiting men as a function of the man's age and the woman's age in Australia and in the United States. The last section examines the risk of being killed by a partner for men in the two types of relationships as a function of the age difference between the partners in Australia and the United States.

In Australia, married men were killed by their partners at a rate of 1.3 men per million married men per annum, whereas cohabiting men were killed at a much higher rate of 21.1 men per million cohabiting men per annum. This pattern where cohabiting men incur a significantly elevated risk of homicide victimization by a partner when compared to the risk incurred by married men replicates the findings of Shackelford [2001] for the United States. Shackelford [2001] reported that cohabiting men in the United States incurred over 10 times the risk of being killed by their partners than did married men. It is important to set these data in the context of the risk of homicide of men by non-partners. Only 10 per cent of men are killed by a partner, with most men being killed by another male, usually a friend or acquaintance [Mouzos, 2001]. However, when women kill in Australia, they are most likely to kill someone within their own family, usually an intimate partner [Mouzos, 2001]. Although the risk of homicide victimization for men is greater by a non-partner, women are at greater risk of being killed by an intimate partner than a non-partner. Close to three-fifths 
of women killed in Australia are killed by a male intimate partner [Mouzos, 2001]. Similar patterns have been identified for the United States [see, e.g., Daly and Wilson, 1988]. Forthcoming research will examine the risk of partner killing by men as a function of age and relationship type as well [Shackelford and Mouzos, in preparation].

Figure 1 shows the rates of partner-killing for married men (clear bars) and for cohabiting men (dark bars) as a function of the man's age in Australia and in the United States. Whether the homicide occurred in Australia or in the United States, the comparative analysis indicates that, among married men, the risk of being killed by a partner is greatest for the youngest men. In Australia, married men aged less than 25 years incur about 4.5 times the risk of homicide as men in the 25-34 age group, and about three times the risk of men in the 35-44 age group. In the United States, married men who are less than 25 years old incur about 1.5 times the risk of homicide as men in the 25-34 age group, and about two times the risk of men in the 35-44 age group.

Although the age-risk pattern for married men is similar in Australia and the United States, the picture changes somewhat when the risk pattern for cohabiting men is examined. In Australia, among cohabiting men, men in the 65 and older age group incur the greatest risk of being killed by a partner. Men in this age group incur over five times the risk of men in the youngest age group. Among cohabiting men in the United States, middle-aged men, in the 45-64 age group, incur the greatest risk of being killed by a partner. Men in this age group incur over four times the risk of men in the youngest and oldest age groups.

Figure 2 presents partner killing perpetration rates for married women (clear bars) and for cohabiting women (dark bars) in Australia and in the United States. The risk patterns for married women killing a partner in Australia replicate the results presented by Shackelford [2001] for the United States. The risk of killing a partner in Australia and in the United States

Australia

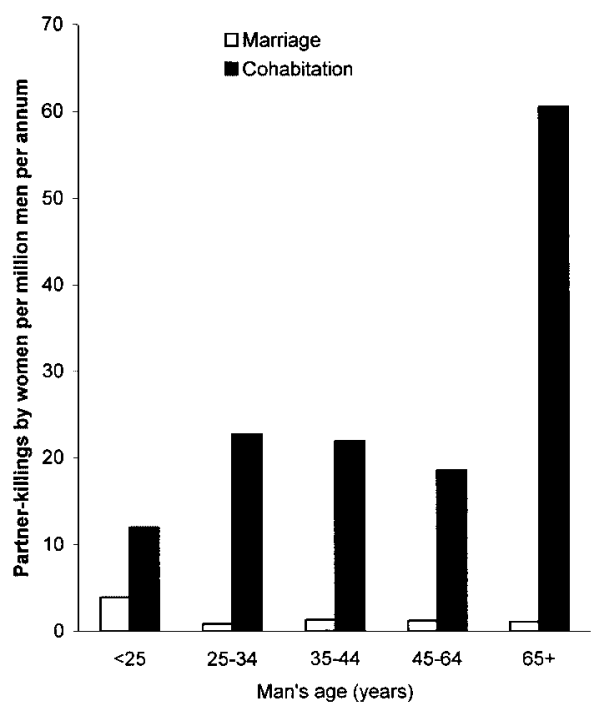

United States

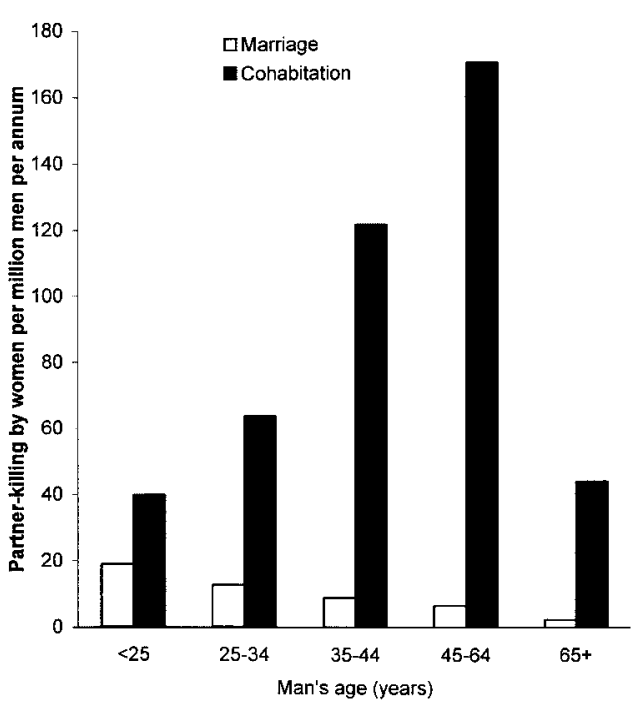

Fig. 1. Partner-killings by women per million men per annum as a function of relationship type and man's age (Source: Australian Institute of Criminology, National Homicide Monitoring Program (NHMP) 1989-2000, [computer file]; Shackelford, 2001). 
Australia

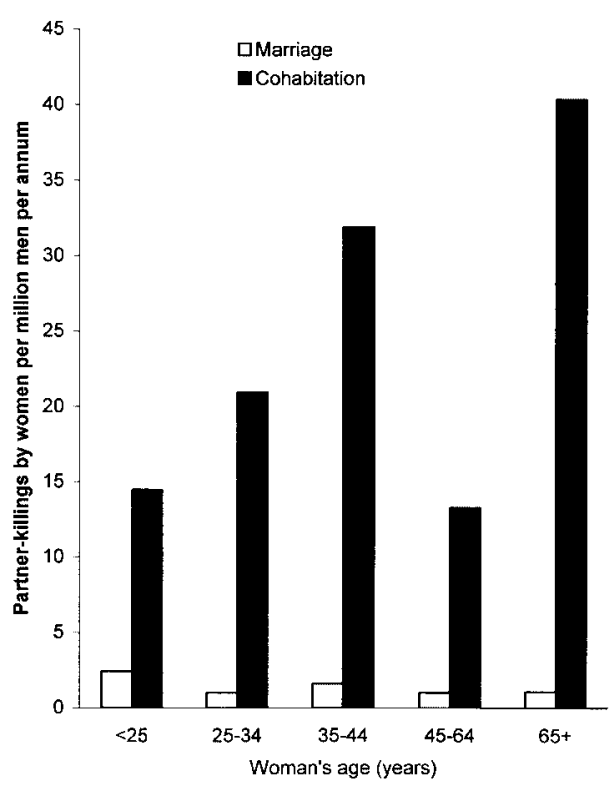

United States

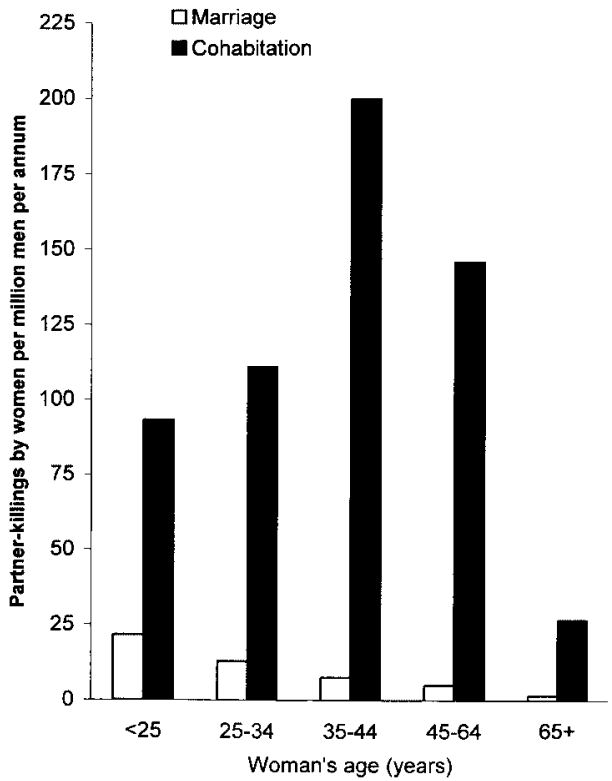

Fig. 2. Partner-killings by women per million women per annum as a function of relationship type and woman's age (Source: Australian Institute of Criminology, National Homicide Monitoring Program (NHMP) 1989-2000, [computer file]; Shackelford, 2001).

is highest for married women in the youngest age group (less than 25 years) and decreases with the woman's age. For cohabiting women, in contrast, the age-risk pattern is somewhat different between Australia and the United States. In Australia, the risk of partner-killing by women is highest for cohabiting women in the oldest age group (65 years and older), whereas in the United States the risk of partner-killing by women is highest for women in the 35-44 age group. Much weight should not be attributed to this cross-national difference, however, given the large relative standard error (about twice the mean) associated with Australian population figures for cohabiting couples in the oldest age group. Discounting the oldest age group of women, for which the results are least reliable, the results suggest that in Australia and in the United States, the risk of partner killing increases with the woman's age for cohabiting women, up to middle age.

Table II (Australia) and Table III (United States) outline the rates of partner-killing by women per million married couples per annum (top figure in each cell) and per million cohabiting couples per annum (bottom figure in each cell, in parentheses) as a function of the ages of the partners. The risk of homicide by a partner is greater for cohabiting men than for married men, for both Australia and the United States. Although there is no discernable pattern in the age-risk of men being killed by their wives in Australia, the age-risk pattern for cohabiting men follows that observed in the United States by Shackelford [2001]. Cohabiting men aged less than 25 years, for example, incur the greatest risk of partner-killing when mated to women aged 35-44 years, for both countries. As another example, and also for both countries, cohabiting men in the 45-64 age group incur the greatest risk of partner-killing when mated to women aged 25-34 years. 
Table II. Australia: Partner-Killings by Women per Million Married Couples per Annum (Top Figure) and Per Million Cohabiting Couples Per Annum (Bottom Figure in Parentheses) by Man's Age and Woman's Age (Source: Australian Institute of Criminology, National Homicide Monitoring Program (NHMP) 1989-2000, computer file)

\begin{tabular}{lccccc}
\hline & \multicolumn{5}{c}{ Woman's age } \\
\cline { 2 - 6 } Man's age & $<25$ & $25-34$ & $35-44$ & $45-64$ & $65+$ \\
\hline$<25$ & 1.4 & 0.0 & 0.0 & 0.0 & 0.00 \\
& $(6.1)$ & $(0.0)$ & $(50.5)$ & $(0.0)$ & $(0.0)$ \\
$25-34$ & 06 & 0.2 & 2.6 & 0.0 & 0.0 \\
& $(7.9)$ & $(8.7)$ & $(33.8)$ & $(0.0)$ & $(0.0)$ \\
$35-44$ & 0.0 & 0.9 & 0.6 & 0.0 & 0.0 \\
& $(18.2)$ & $(9.9)$ & $(9.8)$ & $(14.7)$ & $(0.0)$ \\
$45-64$ & 0.1 & 0.3 & 0.9 & 0.7 & 0.0 \\
& $(0.0)$ & $(46.6)$ & $(14.4)$ & $(7.7)$ & $(0.0)$ \\
$65+$ & 0.0 & 0.0 & 0.0 & 0.2 & 0.2 \\
& $(0.0)$ & $(0.0)$ & $(0.0)$ & $(0.0)$ & $(0.0)$ \\
\hline
\end{tabular}

Table III. United States: Partner-Killings by Women per Million Married Couples per Annum (Top Figure) and Per Million Cohabiting Couples per Annum (Bottom Figure in Parentheses) by Man's Age and Woman's Age (Source: Shackelford, 2001)

\begin{tabular}{lccccc}
\hline & \multicolumn{5}{c}{ Woman's age } \\
\cline { 2 - 6 } Man's age & $<25$ & $25-34$ & $35-44$ & $45-64$ & $65+$ \\
\hline$<25$ & 20.0 & 24.0 & 35.9 & 4.8 & 0.0 \\
& $(20.5)$ & $(30.3)$ & $(114.0)$ & $(8.8)$ & $(0.0)$ \\
$25-34$ & 21.2 & 11.2 & 13.2 & 30.0 & 10.5 \\
& $(34.4)$ & $(33.0)$ & $(89.3)$ & $(129.2)$ & $(0.0)$ \\
$35-44$ & & & & 11.7 & 10.5 \\
& 67.6 & 14.1 & $(72.0)$ & $(101.4)$ & $(21.1)$ \\
$45-64$ & $(61.0)$ & $(74.4)$ & 9.7 & 0.7 & 6.3 \\
& 60.6 & $(120.6)$ & $(108.0)$ & $(77.9)$ & $(27.2)$ \\
$65+$ & $(97.7)$ & 40.1 & 33.0 & 3.9 & 1.4 \\
& 52.6 & $(72.4)$ & $(79.0)$ & $(25.8)$ & $(11.4)$ \\
\hline
\end{tabular}

Figure 3 is constructed from the data presented in Tables II and III, respectively, and illustrates the risk of partner killing by women as a function of the age difference between partners, in categories. In the figure, "1" indicates a one-category age difference, " 2 " indicates a two-category age difference, and so on. Positive values refer to categorical differences in which the man is older than the woman, whereas negative values refer to categorical differences in which the woman is older than the man. " 0 " refers to cases in which the man and woman are in the same age category. The age categories used to generate the 

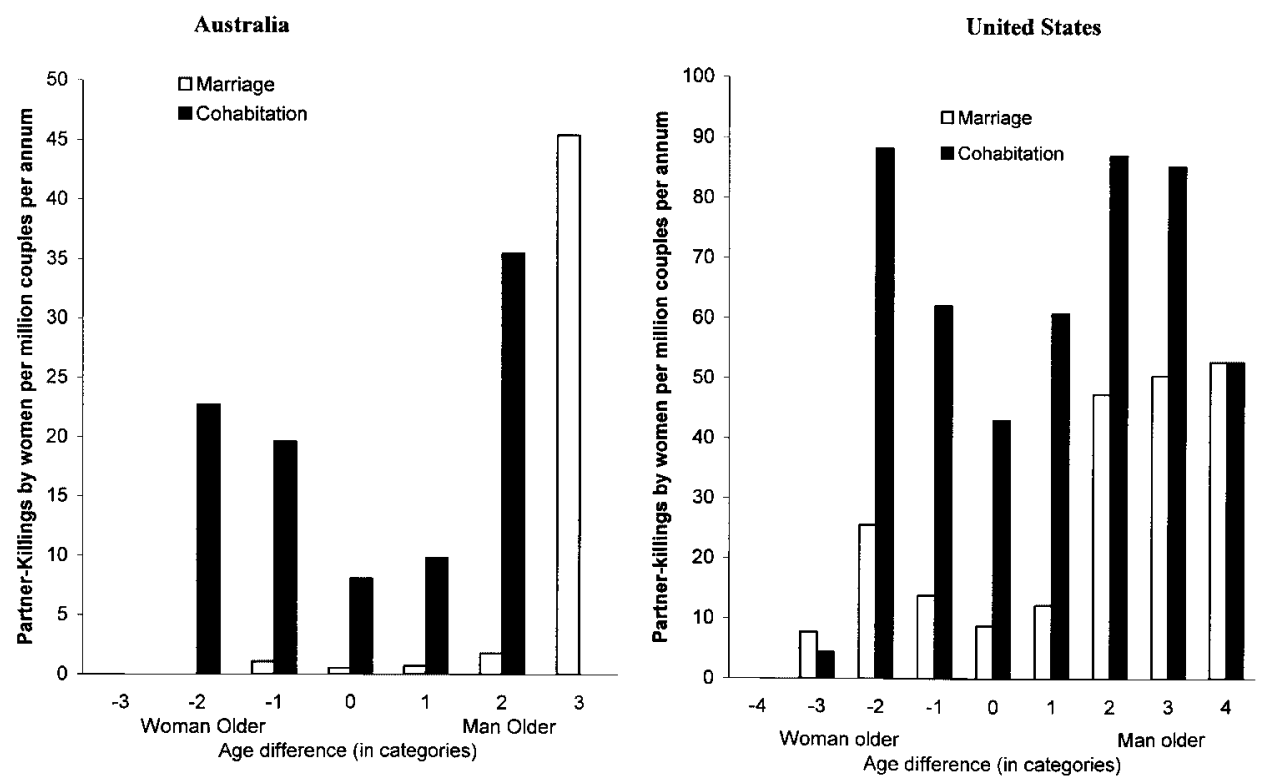

Fig. 3. Partner-killings by women per million couples per annum as a function of relationship type and age difference between partners, in categories (Source: Australian Institute of Criminology, National Homicide Monitoring Program (NHMP) 1989-2000, [computer file]; Shackelford, 2001).

categorical differences for Figures 3 are, in years: less than 25, 25-34, 35-44, 45-64, and 65 and older. As noted in Shackelford [2001], these age groupings maximize the comparability of the results across relationship type. Figure 3 shows that, in Australia and in the United States, for both marital and cohabiting relationships, partner-killing rates for men mated to older women and for men mated to younger women are higher than partner-killing rates for men mated to same-age women. In Australia, for married men, the homicide rate for men mated to women who are either younger or older by one age category is one to two times higher than the homicide rate for men mated to same-age women. As expected, the risk for cohabiting men is significantly greater. The rate of homicide victimization for cohabiting men mated to women who are two age categories younger is almost three times higher than the homicide rate for men mated to same-age women, and the homicide rate for men mated to women who are two age categories older is over four times higher than the homicide rate for men mated to same age women. Shackelford [2001] noted similar patterns in the United States national-level data. Shackelford [2001] reported that for both married men and cohabiting men, the homicide rate for men mated to women who are either younger or older by two age categories is over two times higher than the homicide rate for men mated to sameage women.

\section{DISCUSSION}

Using national-level homicide data and relevant population estimates for Australia and the United States, we calculated partner-killing rates by women by type of relationshipcohabiting or marital, by the ages of the partners, and by the age difference between 
partners. Men in cohabiting relationships incur a significantly higher risk of homicide than men in marital relationships (16 times higher in Australia, 10 times higher in the United States). This cross-national finding indicates that the increased risk of partner-killing faced by cohabiting men crosses international boundaries, and is not a pattern specific to the United States [or Canada, see Wilson et al., 1993]. The current study replicates many of the key patterns reported by Shackelford [2001], as well as those reported by Daly and Wilson [1988], Wilson et al. [1993], and Wilson and Daly [1994] for national-level Canadian data.

The replication of the findings in Australia is strong evidence that the patterns observed in the United States and Canada are not unique to those countries, but that they occur elsewhere, such as in Australia. Although the rates of partner-killing by women in marital and cohabiting relationships are lower in Australia than in the United States, the patterns are similar across the two countries. Men in cohabiting relationships are faced with an elevated risk of being killed by their partners when compared to married men in both Australia and in the United States. Another risk pattern replicated in both countries is that, within marital relationships, the risk of homicide victimization decreases with a man's age. The risk of homicide victimization for cohabiting men is highest for those in the oldest-aged group in Australia. In the United States, the pattern is somewhat different, with middle-aged cohabiting men incurring the highest risk of homicide victimization. The Australian population estimates for this oldest-aged group are of questionable reliability, however, making it difficult to interpret this potential cross-national difference.

Homicide perpetration rates were highest for younger married women and for older cohabiting women. This pattern is documented in both countries. The current study documents that, in Australia, the homicide victimization risk faced by men from their partners increases with greater age difference between partners. This finding replicates that identified by Shackelford [2001] in his examination of partner killing by women in the United States.

The homicide victimization rates in the United States are higher than those in Australia [see Mouzos, 2002]. The fact that the current study reveals similarities in the patterns of partner killing by women as a function of relationship type, age of the partners, and age difference between partners, contributes to our understanding of differential risks in homicide victimization within intimate relationships. The findings suggest that the differential patterns observed are "real" and not a function of sampling error or, for example, unique features of a particular nation.

This research indicates that cohabiting males incur an elevated risk of homicide victimization by a female partner when compared to married males. This finding has important implications for policy, especially because there has been an observed decline in the marriage rate, with more couples choosing to live in a cohabiting relationship as opposed to getting married [see, e.g., Wilson, 2002].

One next step for further research is to examine whether the patterns replicated in this study also obtain if the gender of the perpetrator and victim is reversed. Do cohabiting women compared to married women face an elevated risk of victimization from their male partners, and do these patterns replicate cross-nationally? Given that women are more likely than men to be killed by an intimate partner, differences in risk associated with relationship type may be less pronounced for partner-killings by men. Indeed, recent research in the United States has found a decline in intimate partner homicide for women [see Dugan, Nagin, and Rosenfeld, 1999]. Further research in this area will assist in gaining a more indepth understanding of the elevated risks associated with cohabiting relationships versus 
marital relationships (with women as both victims and offenders), and whether risk patterns examined in the current research operate similarly for men who are killed by female partners and for women killed by male partners. Such research will assist in determining, for example, which factors found in marital relationships are responsible for reducing the risk of homicide victimization and offending, and whether a focused analysis of these factors can be used to formulate prevention policies aimed at reducing the risk of intimate partner homicide faced by men and women in cohabiting relationships.

\section{REFERENCES}

Breault K, Kposowa A. 1997. The effects of marital status on adult female homicides in the United States. Journal of Quantitative Criminology 13: 217-230.

Browne A. 1997. Violence in marriage: Until death do us part? In AP Cardarelli (Ed.), Violence between intimate partners (pp. 48-69). Boston: Allyn and Bacon.

Browne A, Williams KR. 1993. Gender, intimacy, and lethal violence: Trends from 1976 through 1987. Gender \& Society 7:78-98.

Carcach C, James M. 1998. Homicide between intimate partners in Australia. Trends \& Issues in Crime and Criminal Justice, no. 90. Canberra: Australian Institute of Criminology. Cardarelli AP (Ed.). 1997. Violence between intimate partners. Boston: Allyn \& Bacon.

Daly M, Wilson M. 1988. Homicide. Hawthorne, NY: Aldine de Gruyter.

Dugan L, Nagin DS, Rosenfeld R. 1999. Explaining the decline in intimate partner homicide: The effects of changing domesticity, women's status, and domestic resources. Homicide Studies 3:187-214.

Ewing CP. 1997. Fatal families. Thousand Oaks, CA: Sage Publications. Federal Bureau of Investigation 2001. Uniform Crime Reports: Crime in the United States 2001. Washington DC: United States Department of Justice.

Gartner R, McCarthy B. 1991. The social distribution of femicide in urban Canada 1921-1988. Law and Society Review 25:287-311.

Lansdowne R, Bacon W. 1982. Women Homicide Offenders in N.S.W. Sydney: Feminist Legal Action Group. Lawrence JM. 1985. Women who kill. Queensland: Lawrence.

Mouzos J. 1999. Femicide: The killing of women in Australia. Research and Public Policy Series, no. 18. Canberra: Australian Institute of Criminology.

Mouzos J. 2001a. Homicidal encounters: A study of homicide in Australia, 1989-1999. Research and
Public Policy Series, no. 28. Canberra: Australian Institute of Criminology.

Mouzos J. 2001b. Femicide in Australia: Findings from the National Homicide Monitoring Program. In: DEH. Russell,RA. Harmes (Eds.), Femicide in global perspective (pp. 166-175). Ithaca, NY: Columbia University Teachers College Press.

Mouzos J. 2002. Homicide in Australia, 2000-2001 National Homicide Monitoring Program (NHMP) Annual Report. Research and Public Policy Series, no. 40. Canberra: Australian Institute of Criminology.

Polk K. 1993. A Scenario of masculine violence: Confrontation homicide. In $\mathrm{H}$ Strang, S Gerull (Eds.), Homicide (pp. 35-51). Canberra: Australian Institute of Criminology.

Polk K. 1994. When men kill. Cambridge, NY: Cambridge University Press.

Shackelford TK. 2001. Partner-killing by women in cohabiting relationships and marital relationships. Homicide Studies 5:253-266.

Shackelford TK, Buss DM, Peters J. 2000. Wife killing: Risk to women as a function of age. Violence and Victims 15:273-282.

Wallace A. 1986. Homicide. Sydney: New South Wales Bureau of Crime Statistics and Research.

Wilson JQ. 2002. The marriage problem. New York: Harper Collins.

Wilson M, Daly M. 1993. Spousal homicide risk and estrangement. Violence and Victims 8:3-16.

Wilson M, Daly M. 1994. Spousal homicide. Juristat 14:1-15.

Wilson M, Daly M, Wright C. 1993. Uxoricide in Canada: Demographic risk patterns. Canadian Journal of Criminology 35:263-291.

Wilson M, Johnson H, Daly M. 1995. Lethal and nonlethal violence against wives. Canadian Journal of Criminology 37:331-361.

Wolfgang M. 1958. Patterns of Criminal Homicide. Philadelphia: University of Pennsylvania Press. 